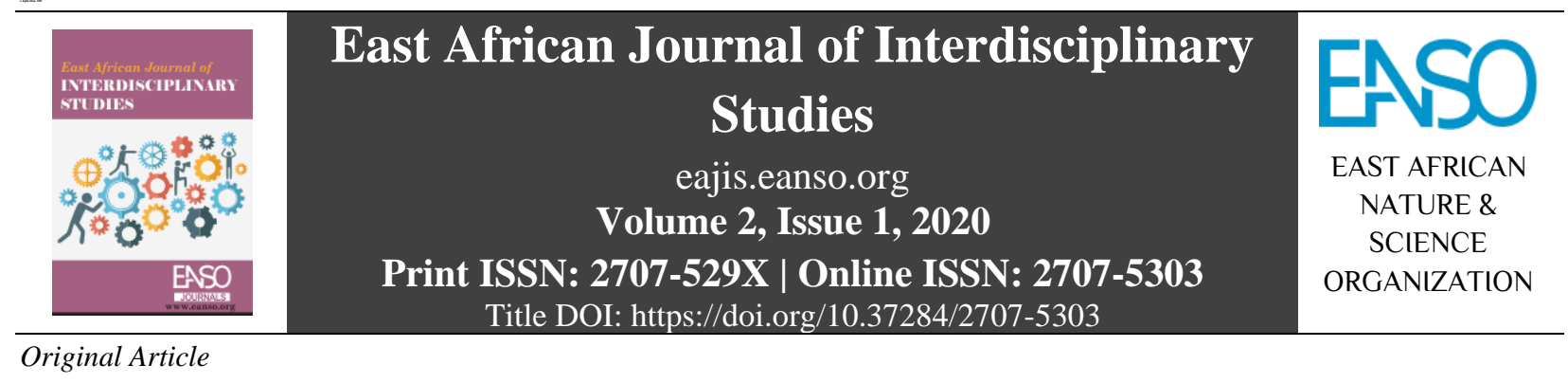

\title{
The Role of Hyperrealism in Painted Portraiture -Engaging Culture: Analysis of Portraiture by Eddy Ochieng
}

\author{
Dr. Kamau Wango, $P h D^{1 *}$
}

1 Department of Fine Art and Design, Kenyatta University, P. O. Box 43844 - 00100, Nairobi, Kenya; ORCID: https://orcid.org/0000-0002-0185-1355.

* Author for Correspondence email: kamauwango@gmail.com.

Article DOI: https://doi.org/10.37284/eajis.2.1.246

\section{Date Published: ABSTRACT}

09 December 2020 Portraiture remains one of the most fascinating genres of Art; it is engaging, intriguing and often, perhaps, a little controversial. Portraiture

Keywords: has been executed through the centuries in a variety of styles and media and for different purposes, from the ancient Egyptian cave paintings,

Portraiture, Hyperrealism, Visual Culture, Photography, New Reality. through the medieval civilisations to the renaissance, new world, the great divide, modern era and ultimately to post-modernism pop art portraiture. One question that has always resurfaced in the interrogation of portraiture is what is the role of portraiture. There have also been incessant questions about the effectiveness or even need for some painting styles used in portraiture as well as other genres. Within contemporary Art, one of these styles that have often generated passionate arguments between those who love it and those who do not subscribe to it is hyperrealism. Detractors of hyperrealism, which started in the early 1970s, have consistently argued that by virtue of its reliance upon photography, what it seeks to portray is already achieved through photography and hence it is artistically 'pointless' since it serves no further visual purpose. Dwelling specifically on this artistic 'pointlessness', they have even questioned whether hyperrealism is Art or just a very refined and admirable show of skill. Proponents of hyperrealism, however, bask in the satisfaction that it retrieves all photographic cues from a digital image or a high-resolution photograph and converts or transforms these into a different realm of artistry and perfection by the placement of even more minute and meticulous details that would otherwise be invisible to the eye. This creativity culminates in an entirely new form, an 'illusion of reality' more artistically and visually engaging than the original photograph. The detractors, therefore, state that since hyperrealism is derived from photography as a 
reference base, then it is redundant as a style. In order to address this query, this paper examines the role of hyperrealism in modern portraiture as it is specifically applied to Kenyan portraiture executed by Eddie Ochieng', an outstanding Kenyan hyperrealist, in order to determine its own 'visual efficacy' as a sub-genre. The portraiture itself, as featured in this paper, focuses on aspects of culture to explore the overall visual impact as a result of the application of hyperrealism.

\section{APA CITATION}

Wango, K. (2020). The Role of Hyperrealism in Painted Portraiture -Engaging Culture; Analysis of Portraiture by Eddy Ochieng. East African Journal of Interdisciplinary Studies, 2(1), 157-179. https://doi.org/10.37284/eajis.2.1.246

\section{CHICAGO CITATION}

Wango, Kamau. 2020. "The Role of Hyperrealism in Painted Portraiture -Engaging Culture; Analysis of Portraiture by Eddy Ochieng”. East African Journal of Interdisciplinary Studies 2 (1), 157-179. https://doi.org/10.37284/eajis.2.246.

\section{HARVARD CITATION}

Wango, K. (2020) "The Role of Hyperrealism in Painted Portraiture -Engaging Culture; Analysis of Portraiture by Eddy Ochieng", East African Journal of Interdisciplinary Studies, 2(1), pp. 157-179. doi: 10.37284/eajis.2.1.246.

\section{IEEE CITATION}

K. Wango, "The Role of Hyperrealism in Painted Portraiture -Engaging Culture; Analysis of Portraiture by Eddy Ochieng", EAJIS, vol. 2, no. 1, pp. 157-179, Dec. 2020.

\section{MLA CITATION}

Wango, Kamau. "The Role of Hyperrealism in Painted Portraiture -Engaging Culture; Analysis of Portraiture by Eddy Ochieng”. East African Journal of Interdisciplinary Studies, Vol. 2, no. 1, Dec. 2020, pp. 157-179, doi:10.37284/eajis.2.1.246.

\section{INTRODUCTION}

The significance of portraiture as a mode of visual communication and expression has never been in doubt through the ages; it is one of the most celebrated sub-genres of painting. What has often been debated is the extent to which portraiture achieves or does not achieve this expectation. It has often been asked who indeed is responsible for interpreting the image in a portrait; is it the subject (or sitter), who knows himself or herself best, is it the introspective artist attempting to depict his or her interpretation and perception, or is it be the viewer who attempts to unravel the message in the image but is almost always met by the paradox of the mysterious face? Indeed, other queries have gravitated around whether it is even possible to label a portrait as representing the 'personality' and 'character' of the subject particularly in view of the possibility of the presence of allegorical factors. Therefore, beyond the study of likeness or realistic representation which is a major purpose of portraiture, there must exist other roles that portraiture fulfils since not all portraiture is realistic nor seeks to only be representational. Hensher (2005) poses an interesting question in the interrogation of portraiture. Focusing upon the sitters who remain an intriguing phenomenon in portraiture by the way they gaze at the viewer, he asks; 'Who are they? Who are they looking at? Portraits can make us feel we are intruding on a very private scene; this is their appeal'.

\section{Role of Portraiture}

It can be said that over time, portraiture has evolved to fulfil many roles and inspire many artistic endeavours beyond its traditional representational or commemorative purpose. 
Different people assign different meanings to the role of portraiture. Gersh-Nesic (2019) observes that 'portrait paintings go beyond simple documentation; it is the artist's interpretation of the subject'. Arguing that portraiture must be considered as an integral part of contemporary Art, Pereira (2015) notes that 'besides the information that a portrait transmits to its viewers regarding the appearance of the subject, it's also important for contemporary art that a portrait contains a context, identity questions, social issues.' Nairne (2006) acknowledges that photography did have an impact on the traditional role of painted portraiture but is equally quick to add that that did not necessarily amount to a displacement; it created opportunities by shifting attention to other possibilities, 'But my proposition here is not that photography has displaced painted portraiture, but that it has changed the encounter between subject and artist, and altered part of the context in which painted portraits are created.' However, in the era of digital imagery in contemporary Art, there is still a chance for a new kind of dispensation in painted portraiture that underscores its durability. Nairne writes:

The fast-changing landscape of surveillance and the globalisation of digital imagery calls for the counterpoint of intense, 'local' imagery contained within a painting. The possibilities of allegory and complex meaning are distinct: the symbolic realm can come to the fore. The conveying of character in a painted portrait is specific and dynamic. There is a process described through paint - an intensity to the relationship between artist and sitter which produces a different character from the medium of photography. And it is this intensity, often freed from the conventions of previous periods which, gives a great portrait its authority.

\section{Visual Culture Value}

Since this study focuses on hyperrealistic portraiture as it applies to the cultural subject matter, it inevitably touches on the broader issue of visual culture. Visual culture itself is based on the notion of the visual versus the notion of the culture as seen by the audience or consumer. Portraiture as a genre is part of the Fine arts which form part of the body of "visual arts'. When the visual products of the fine arts, including portraiture, are applied to an aspect of culture whereby the consumer can associate those visual products with recognisable aspects of their cultural heritage, then that amounts to the propagation of visual culture. Subsequently, the portraiture featured in this paper draws significant bearing upon this perspective.

\section{Overview of Portraiture}

This study deals with portraiture in general but delves into hyperrealism in particular and how it is applicable to portraiture in the expression or communication of subject matter, in this case, an aspect of culture. It is, therefore, fitting to briefly examine how the two inter-relate.

Hyperrealism emanates from the use of digital images and high-resolution photographic images that are used as reference resources for the creation of hyperrealistic work. Hyperrealists then develop this photographic image into a new piece of Art described as a new 'reality' that does not exist in the original reference photograph or indeed in the real world. But, hyperrealist artists go even further 
in the development of the reference image; they incorporate as a thematic element in their new 'reality' or new hyperrealistic image, emotional, social, political and cultural elements (Lansroth, 2015). This incorporation of a thematic element becomes specifically important in the application of hyperrealism to portraiture since, by extension, it makes hyperrealism relevant in portraiture. This thematic angle provides the basis upon which artists can utilise any of the elements, be it emotional, social, political, or cultural, to express or communicate a given message in the realm of hyperrealistic portraiture as in the case of this study.

This study focuses on 13 painted hyperrealistic portraiture which features aspects of culture to determine the visual impact of hyperrealism as an artistic style within the realm of portraiture and further, the usefulness of hyperrealistic portraiture as an avenue for visual culture propagation.

\section{HYPERREALISM - AN OVERVIEW}

\section{Hyperrealism and Photography}

As already observed, hyperrealism in its process and outcome endeavoured to artistically clarify and enhance photographic images. The motivating factor in creating hyperrealism is to improve upon details contained in the reference photograph and create a new piece of Art that contains intricate and minute details more refined than those in the reference photograph. Therefore, by using digital images and high-resolution photographs as a base, hyperrealists paint in a minute and meticulous details that transform the image into an illusion of a new reality not present in the reference photograph. Hyperrealistic images are often 10-20 times larger than the photographic reference source yet the details, colours and textures are not only magnified but retain their high-resolution levels through the technique applied. Therefore, one important element of hyperrealism as a style is the ability of the artist, through technique, to retain and enhance details in the enlarged final product where the high resolution is not compromised. These new featured details on the hyperrealistic image are finer and more distinct than what would otherwise be deemed possible to identify on the original photo. Lansroth (2015) observes:

Hyperrealistic painters strived to achieve a different pictorial design overall, by incorporating an element that might not be there in reality. They consciously entailed a softer and much more complex focus on the depicted subject, creating an illusion of a new reality not seen in the original photo.

Photography in portraiture can have its limitations, particularly being impersonal and stiff, but hyperrealists use their creativity to inject a little character to their portraiture, give it a little charm and narrative so that the end result is a complete transformation of the plain reference photograph. Hyperrealists have, however, at times attracted consternation with work that bears such levels of minute and intricate detail that not only does it surpass photography, but it also bears the hallmarks of illusionistic work, since such levels of detailed realism do not actually exist in a real-life environment. Indeed, some people have even questioned whether hyperrealism itself is actually Art or merely a display of very refined skills. This paper contends that whichever way hyperrealism is perceived, it is a useful artistic 
style of presenting portraiture. The paper, therefore, explores and thereby perhaps seeks to demonstrate that there exists a robust relationship between hyperrealism and portraiture and that hyperrealism when applied to portraiture aids in expressing an intended message or communicating a given message, in this case, a cultural message.

\section{Hyperrealism and Photorealism}

Hyperrealism and photorealism have often been thought to refer to the same thing. They are related in approach since they both use a photograph as a reference resource to create an artistic product. They, however, deviate in the actual process and their resultant final product. In photorealism, the artist uses a photograph with the intention of reproducing the image on canvas to resemble or re-enact the realism of the photograph as much as possible; hence the idea is to imitate the image in order to make the final work appear photographic. Hyperrealism, on the other hand, aims to use a photograph as a reference resource to extract detail but with the intention of developing and enhancing those details on canvas to a new level of reality, more graphic than nature. This means that the new product bears such levels of detail that it surpasses the original photograph. Hence, the former aims to imitate the photograph and produce a 'similar' artistic product, while the latter aims to surpass the photograph and create a 'new' artistic product. Bent (2011) provides a good distinction between the two by noting that 'Hyperrealists took the techniques employed much further in that they developed ways of introducing narrative, charm and emotion in their paintings'. In comparing the approach of photorealists who use their skill to imitate and reproduce the details of a photograph, and hyper realists who develop the details further, he concludes;

Instead, the hyperrealist interprets the reference photographs - or in many cases multiple reference photographs - and with the use of artistic licence, and specific and highly individualistic techniques of colouring and detailing, is able to add charm, emotion and 'soul' to his paintings, thus giving to his works a mystical, even magical quality that simply does not exist in photorealist paintings.

It is also notable that photorealism preceded hyperrealism, making its debut in 1969 and the other is 1973 and it is therefore assumed that hyperrealism was a development of photorealism at least in terms of the refinement of technique.

\section{Hyperrealism and Art}

As briefly mentioned in the abstract, hyperrealism has been under scrutiny from critics who argue that as a style, it exists in a state of redundancy since its visual essence is already captured in photography. But on the basis of its stylistic approach, hyperrealism contributes a new dimension to artistic creativity. As already observed, it uses the photograph as a base from which it extracts and further develops details to a heightened level and creates 'new reality', adding a layer of vision that otherwise does not exist. This new hyperrealist product is so fine, it surpasses the normal perception of reality and provides a new and augmented view of reality. This paper posits that in view of its undeniably intricate and captivating creative process, the contribution of its style as well as the superb level of skill of the hyperrealist artist, 
hyperrealism renders itself uniquely useful and hence qualifies as integral Art. Lansroth (2015) concludes that 'undeniably, it is an art form no matter how you look at it, either from the craftsmanship and skill point of view or if you admire the subtle layers of narrative added to the existing image'. In responding to the critics of hyperrealism as Art in this regard, Muoka (2017) asks an insightful question,

'There are artworks which require little or no skill and have gone on to become masterpieces and celebrated as creative expression in recent times. What makes the case of immense discipline, painstaking effort and great level of skill different?'

\section{Hyperrealism and Communication}

Hyperrealism as a style can be said to have the communicative ability because it adds narrative to its final product, unlike photorealism which is said to revolve around skill and imitation. Hyperrealism can be used to mould social, political and cultural messages into realistic artistic depictions by the application of a heightened level of realism that strikes the imagination of the viewer more than just an imitated photograph or even the photograph itself. By so doing hyperrealists add emotion, intent, narration and feeling into their work. Taggart (2018) observes, 'With a broad range of themes, some hyperrealist artists evoke emotional, social, cultural, and political meanings in their art'. This distinction helps the case for hyperrealism being used to express or to communicate the desired message. The ability to heighten the level of detailing can be applied to focus upon and bring attention to a given message. Therefore, hyperrealism and its vivid technique when applied through emotional, social, cultural, and political lenses transform into an avenue of focus through which observers are compelled to view themselves and the world around them. To demonstrate that artists take up hyperrealism with intent and purpose that gives meaning to their work, Cichanowicz (2017) refers to the work of Dzimirsky and observes, 'His work is remarkable because he is able to convey intense emotion within the images. Dzimirsky intends for each of his works to tell a story'.

\section{ANALYTICAL FRAMEWORK}

If hyperrealistic portraiture is seen as Art then it will be analysed as such. The artwork is analysed from mainly three perspectives; form, content, or context, which are then broken down to specific segments of examining a work of Art and which are at play at any given time. They are also interrelated and one is able to understand an art piece by examining one in relation to the other. The analytical framework in this paper combines 'formal analysis' and 'cultural contextualisation', within the wider realm of contextual analysis, since the portraits featured deal with aspects of culture. Contextual analysis in this regard deals with the context in which the work is presented and the relationship with other areas of knowledge with which the work inter-relates, which in this case is the culture of the communities. This combination is important in helping understand the meaning and significance of the portraiture as well as to connect the formal achievements of the portraiture to cultural purposes and meanings.

Formal analysis in itself deals with the formal elements of the portraiture such as line, colour, textures, shapes, value, masses and spaces. It is approached within four basic segments of 
analysis; description, analysis, interpretation and evaluation. Within the formal analysis, Description deals with the immediate visual impact, or what confronts the eyes upon viewing the artwork; how the eyes flow over the work and where the focus is ultimately concentrated upon when examining hyperrealistic portraiture. It is also descriptive of the presence of respective elements and the application of principles of Art. The analysis examines the rendering of the work, in essence focusing on the stylistic approach that the artist embraces as well as the fundamental technique applied and media used to create the Artwork. This includes a detailed look at the effectiveness of the use of elements and the application of principles in order to aid the structure of the composition. This is particularly important in hyperrealism since the use of colour, colour tones, the effect of light and shadows as well as textures are all specific in the manifestation of the heightened level of minute details consistent with the style.
Interpretation seeks to unravel the meaning of the painting by addressing the featured 'content' of the subject matter, in this case, the 'subject' in each portrait as well as any accompanying visual additions. The focus here is the reason, motivation or inspiration that makes the artist embark on the portraiture. Of particular importance to this paper is the emotional response or mood created as well as observing how the artist has created a certain atmosphere in the portraiture. The paper, therefore, seeks to examine the subjects featured in the portraiture to see whether they portray or emanate a 'personality' or whether they tell some sort of story, or whether the portrait in its entirety succeeds in carrying a cultural message. Evaluation refers to an informed opinion on the overall ability or success of the artist to convey an idea based on artistic observation.

\section{ANALYSIS OF WORK}

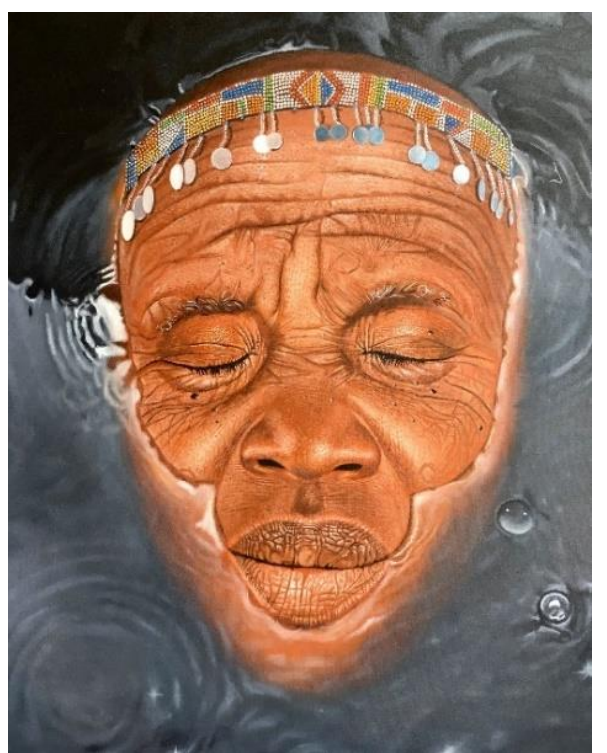

Plate 1: Rebirth; Size: $95 \mathrm{~cm}$ x 140 cm; Medium: Oil on canvas; 2020

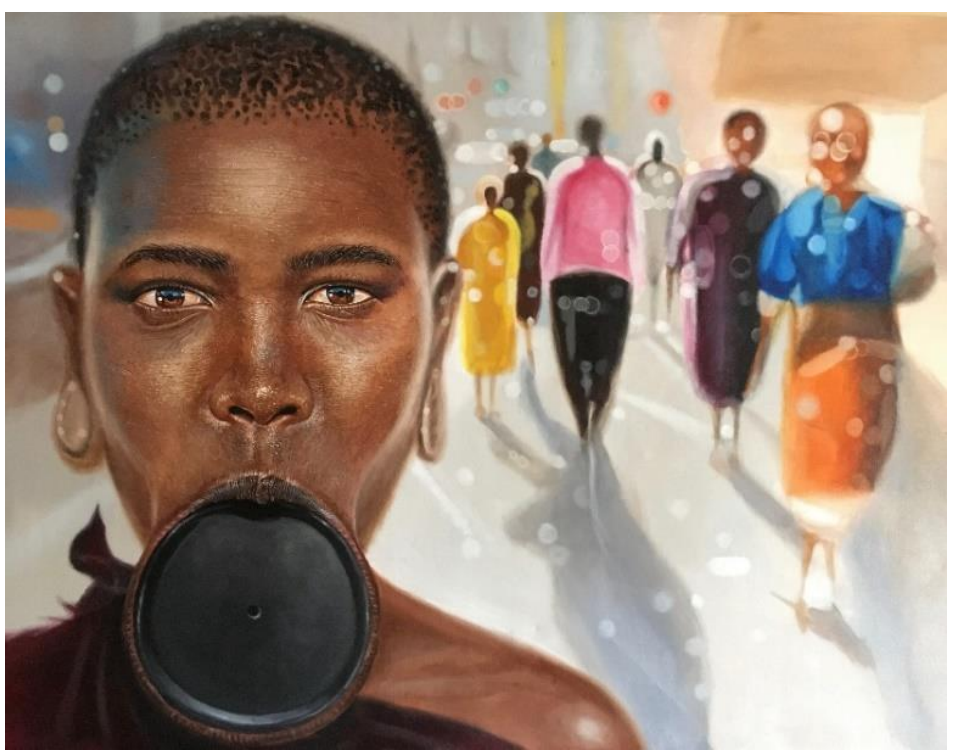

Plate 2: Stand out; Size: $95 \mathrm{~cm}$ x $140 \mathrm{~cm}$; Medium: Oil on canvas; 2020 
Plate 1. An elderly Maasai woman with her face partly submerged in water; almost a show of her dipping in for rejuvenation to enable her spring back to life. When culture is rightly upheld, it propels us back to life, with a well-defined sense of identity and purpose (Artist).

In Rebirth (Plate 1) the elderly Kenyan Maasai woman is almost entirely immersed in water leaving only a section of her face above water. The face shows a minute study of facial details including the texture of the lips and wrinkles around the eyes and forehead. The artist goes out of his way to show some ornaments on her forehead executed with equally meticulous detail. The portrait expresses the calmness of a moment of peace created by the total feeling of harmony between the individual and the water. That facial expression is an artistic testimony to what the artist calls 'rejuvenation'. This is shown through the closed eyes and the suggestion of an uncanny mild smile on the face of the elderly woman. This demonstrates the artist's ability to use portraiture to express what can be termed as 'static emotions'. Unlike laughter, anger, or distress which are highly 'fluid' emotions and are often easily visually expressed, static emotions as described in the context of this paper, are much harder to depict since they portray very little obvious facial characteristics. The portrait successfully portrays an element of serenity, yet there are no obvious facial cues associated with serenity. Through her serenity, the subject intimates to the viewer her feeling of absolute peace and sanctity. Could this be the rejuvenation that the artist refers to?

Plate 2. An unusual sight in the usual place. This is a figure that would turn heads in a busy street. In a world full of personalities, voices and ideologies, only the unusual stand out (Artist).

Culturally, beauty can be interpreted in unique ways. In Stand Out (Plate 2) the girl with a lip Plate is a Mursi girl from Ethiopia; the lip Plate is a mark of youthfulness, beauty and identity and is worn usually by young unmarried girls and young brides. The girl has her lip cut and extended by the use of a sodden plug. The artist studies the face of the girl in great detail showing her smooth youthful African skin, textured hair and sparkling eyes. He uses stylistic contrast to distinguish and deemphasise background figures while highlighting the subject whom he places in the foreground. The portrait is self-explanatory; thoroughly cultural, depicting a specific aspect of the culture of this community in a manner and style that is starkly truthful. The hyperrealism of this portrait jerks the viewer to the reality, and perhaps, the absurdity of this particular aspect of culture in a modern world that leaves in its wake a trail of questions. 


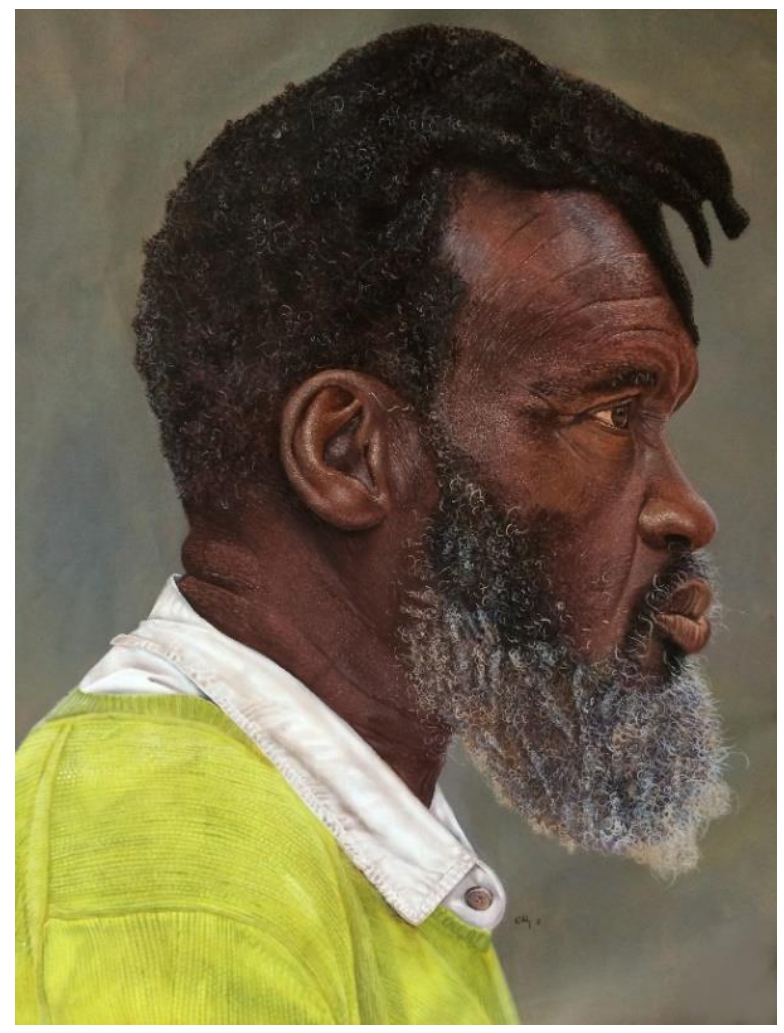

Plate 3: Time and chance; Size: $170 \mathrm{~cm}$ x 120 cm; Medium: Oil on canvas; 2019

Plate 3: This is a portrait of an old man I met while walking in town. The inspiration for this piece emanated from the threeminute conversation I had with him after he told me 'everyone has their appointed time' (Artist).

The portrait of a man Time and chance (Plate 3 ) is an example of how portraiture can be used to study character by extension. By virtue of the detailed style in which the painting has been executed, the textured hair with dreadlocks falling frontwards, the beard and the multitoned face, it allows one to take a closer look at facial features in order to decipher what the holistic facial expression perhaps alludes to. The portrait, executed from the side view, shows a man in deep thought or reflection and even a suggestion of underlying anger. This is depicted by the focused gaze, the frown on the

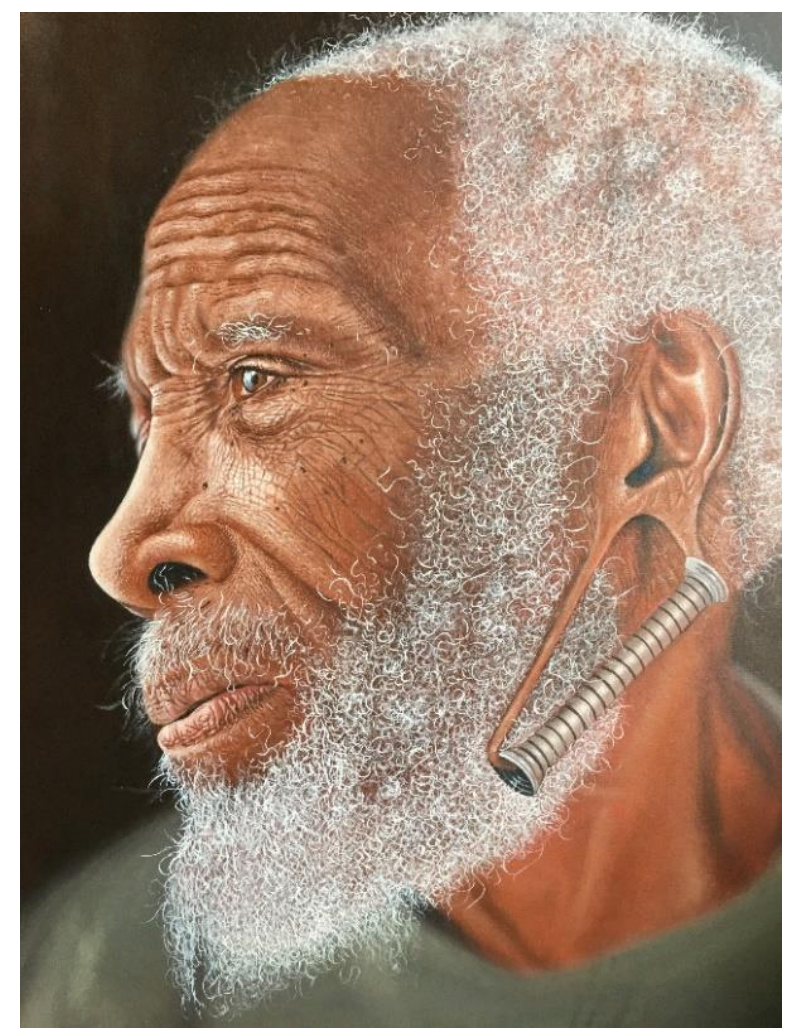

Plate 4: Timeless; Size: $95 \mathrm{~cm}$ x $140 \mathrm{~cm}$; Medium: Oil on canvas; 2019

forehead and the firmly tightened lips. This is further enhanced by the facial structure itself such as the elongated face, the slightly protruding forehead, depressed bridge of the nose and almost non-existent cheekbone. This portrait shows that a face and the way it is portrayed is a visual testimony of a counterstory, the subject's inner soul, which in terms of expression is always a good beginning for appreciating and unravelling why portraits are important.

The artist painted this portrait of the man he talked to in the street in order to portray what he thought best represented that encounter, a demeanour of a man who certainly had an issue about which he wanted to be heard. The portrait succeeds in portraying that this image is not just a nice side view of some individual, but that the subject had something to express. It has 
always been a matter of contention whether an image can depict the 'character' and 'personality' of the subject. This image can be said to 'project' a character that is describable as 'resilient' and 'defiant', the basis of which is the artist's depiction of the impression created by the encounter with the man. In some portraits, this feeling of character and personality is more evident than in others. This is, of course, subjective and founded within the realm of symbolism; momentarily viewed away from the possibilities of allegory.

This paper posits that it is possible for a subject in portraiture, by virtue of his or her appearance, to exude an element of 'character' and 'personality' and that it is visually an effective way of attempting to decipher the individuality of the real person. This is as far as visual possibilities can be stretched and often this visual intuition may not be very far removed from the actual character and personality of the real individual. This implies that allegorical concerns may at times be proven to be redundant. This is, indeed, the beauty of visual analysis; the ability to 'see' what could be, to 'feel' what is concealed, even though one cannot necessarily prove what they are made to feel. What is extractable from the portrait is what the viewer takes away in his or her mind.
Plate 4. True and authentic identity leads to a more fulfilling life, even in old age. This is a Kenyan Maasai elder still adorning a traditional ornament. To the community, culture is timeless (Artist).

In Plate 4, the artist paints a portrait of an elderly Maasai man which can be viewed in two perspectives. The first obvious perspective is the study of the face itself. Unlike the subject in Plate 3, this portrait is that of a calm demeanour of the subject, most likely a very peaceful elderly man in real life. The face is executed in superb detail, with the inclusion of the distant gaze that underscores a character that is thoughtful and wise. The second perspective is the cultural one, depicted by the pierced and stretched ear lobe, which is characteristic of some communities the world over. This brings in the aspect of portraits becoming tools for the propagation of visual culture since what is portrayed resonates with the culture that people can identify with and which they call their own. In view of the two perspectives, the question that such portraits raise is what the intent of the artist is; is it to use the hyperrealistic details of the image to propagate as an aspect of culture or is it for the image to express some other pertinent message. In some cases, like in this particular portrait, the artist can achieve both objectives (See overview - the visual essence of hyperrealism on portraiture). 


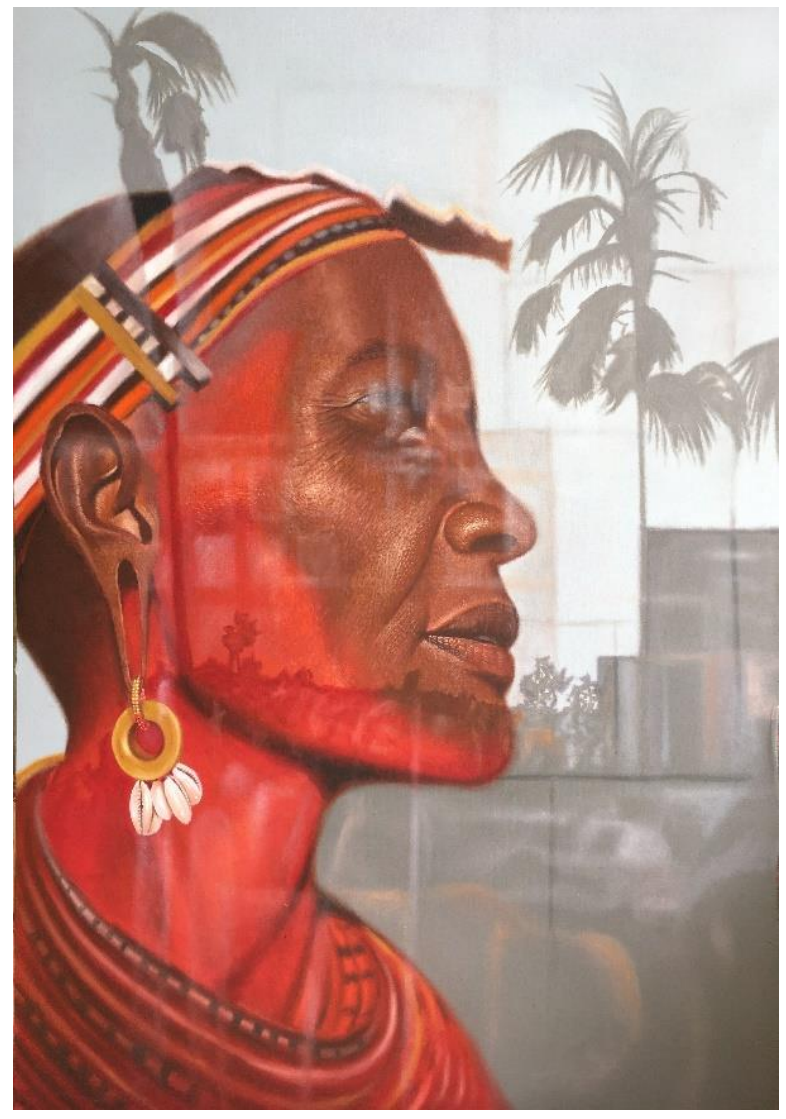

Plate 5: Through the lens; Size: $95 \mathrm{~cm}$ x 140 cm; Medium: Oil on canvas; 2020

Plate 5. A Kenyan Samburu woman staring at the city through a glass window (Artist)

Plate 6. This is a portrait of a Mundari tribesman (Sudan) in spectacles. Quite a rare picture. Often a symbol of the learned, the spectacles here shows that education should not erode culture (Artist).

Through the lens (Plate 5) depicts a Samburu woman who is mesmerised by life in the city, underscoring the contrast between culture and modern life. She is depicted in full traditional regalia including intricate bright coloured traditional ornaments such as the beaded necklace. She also has red ochre applied on her face and neck. The glass window through which she views the city is symbolic of the

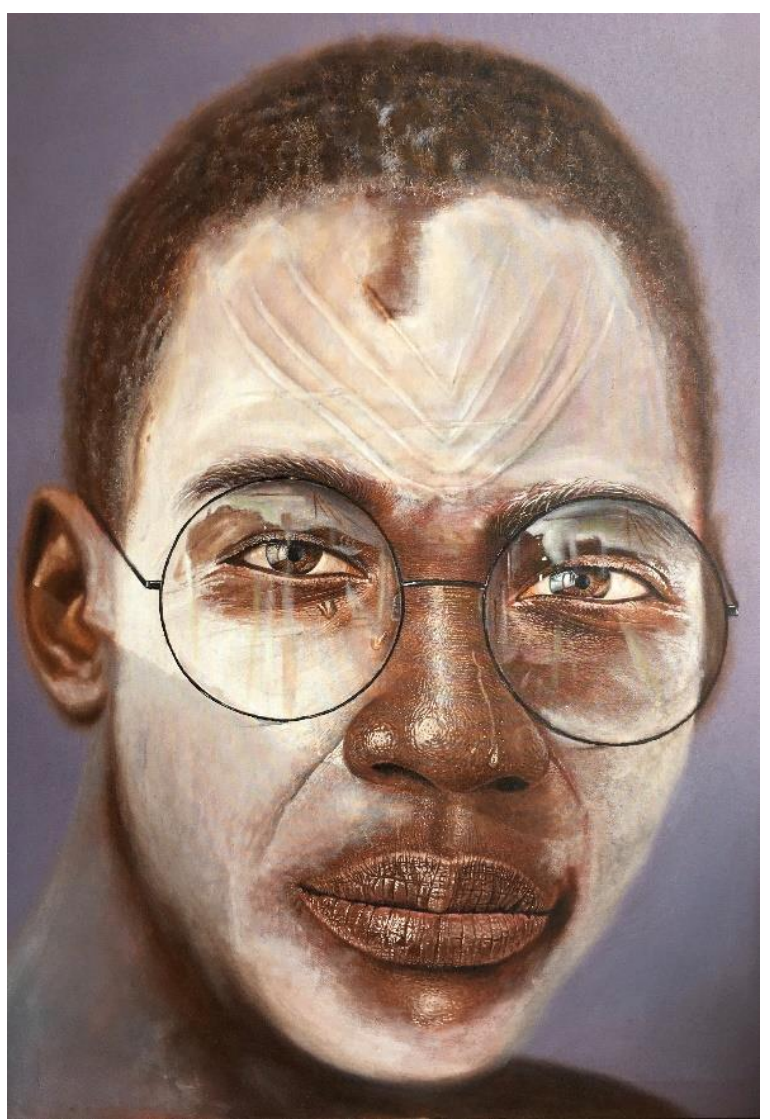

Plate 6: Dauntless; Size: $95 \mathrm{~cm}$ x $140 \mathrm{~cm}$; Medium: Oil on canvas; 2020

sharp divide between the dictates of her culture and the magic of modernisation, a bridge she cannot cross.

Dauntless (Plate 6) depicts a young Mundari tribesman's face, well-executed with sharp, penetrative eyes and well-textured hair and lips as well as the application of white traditional ash, obtained from dung fire. The portrait depicts a man at the crossroads of traditional culture and modernity underscored by the white ash on his face and the V-shaped ritual facial scarring on the one hand, and the adornment of spectacles on the other. The portrait identifies the white ash (which is used culturally as an insect repellent and also serves as an antiseptic) and the ritual facial scarification (which is a cultural practice 
among the Mundari community of South Sudan and is a symbol of tribal identity and beauty for the women as well as a bridge to adulthood for young boys) as the main cultural elements. The spectacles are, of course, a symbol of the interventions of modern life and hence become an expression of the confluence between tribal culture and modern lifestyle which is a significant statement extracted from the portrait.

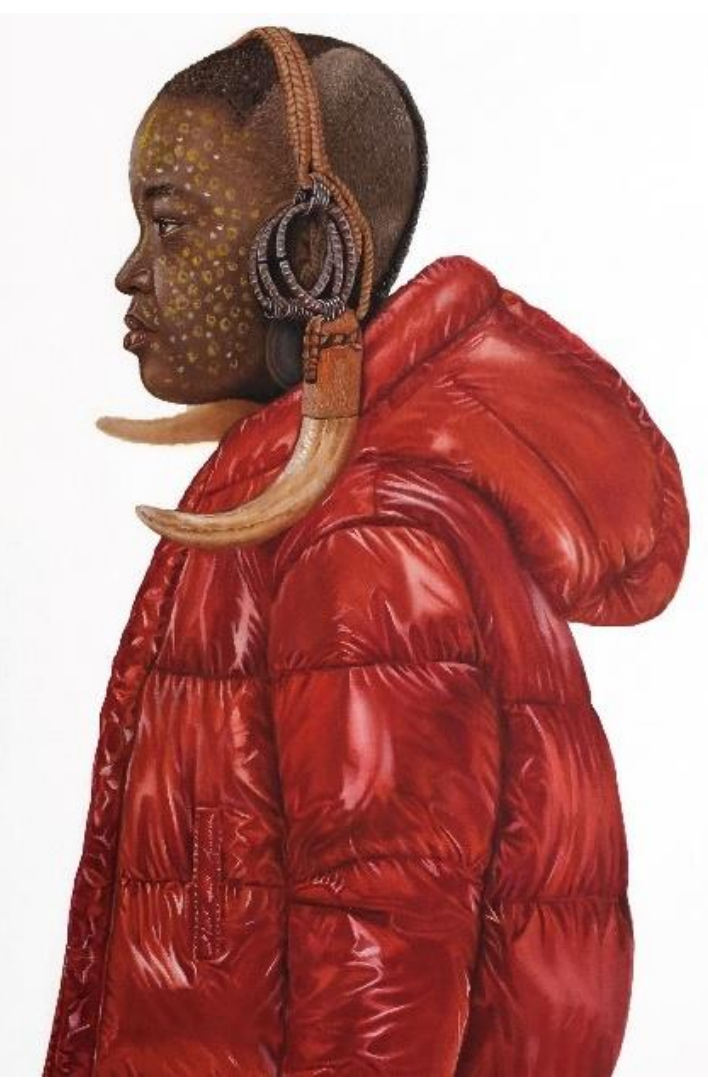

Plate 7: Way out; Medium: Oil on canvas; Size: $95 \mathrm{~cm} \mathrm{x} 140 \mathrm{~cm} ; 2020$

Plate 7. This is a Mursi tribe young girl from Ethiopia in a winter jacket. Ethiopia lies in the tropics which is fairly warm so the winter jacket scenario would be uncommon. Breaking borders often completely assimilates people to the host community, leaving behind their parent culture in an attempt to fit in (Artist).

In way out (Plate 7) the Mursi girl is an image of youthful beauty. The girl's face is very well detailed with the use of tones, shadows and

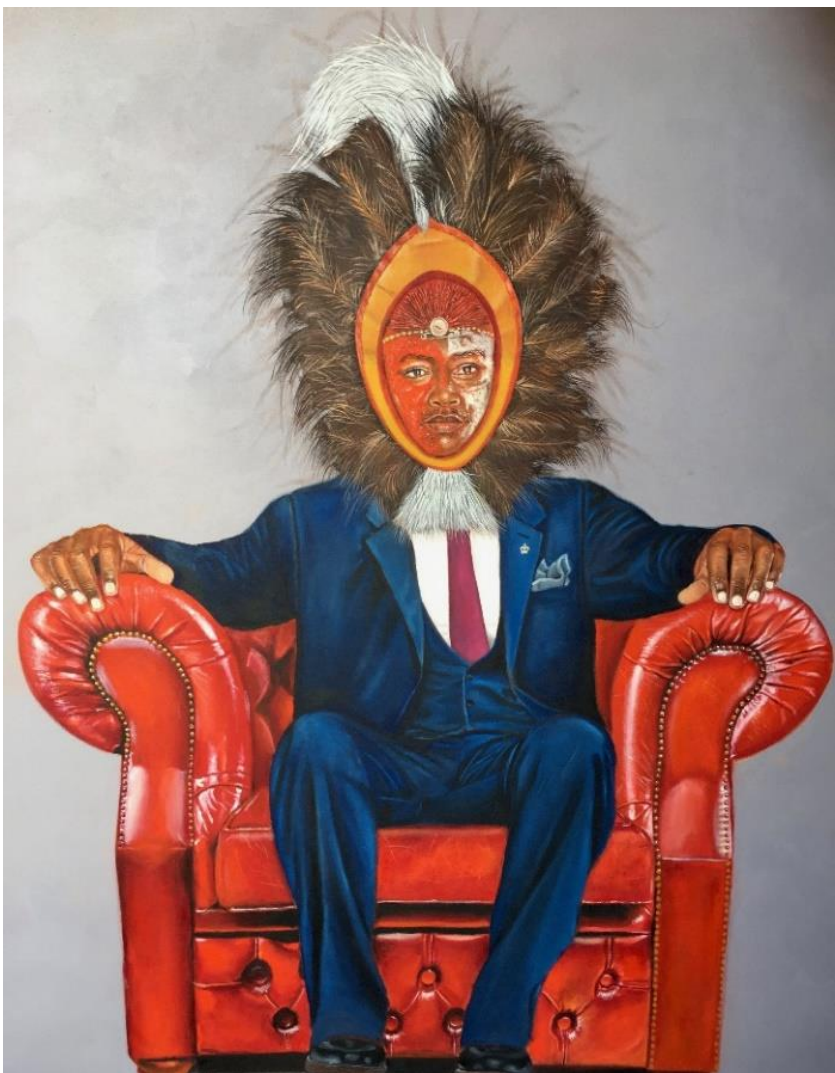

Plate 8: Alpha; Size: $107 \mathrm{~cm} \mathrm{x} 150 \mathrm{~cm}$; Medium: Oil on canvas; 2020

textural effects that distinguish her hair and the shaven parts of her head. Her face is decorated with multi-coloured polka-dots and her head is adorned with a leather headdress composed of interwoven leather straps and warthog tusks attached at the end. She also wears a red winter jacket as a prominent feature even though it is not a local cultural item. This is a significant depiction since the Mursi people of Ethiopia are not known to inter-mingle with outsiders. This portrait is used to depict an aspect of Mursi culture as well as demonstrate the 
interaction with the outside world, probably as the artists alludes, to suggest some indication of assimilation.

Plate 8. This particular pose was inspired by Abraham Lincoln's statue which symbolises boldness, greatness and authenticity. True leadership goes hand in hand with values. In an African context, modernity should be informed by culture (Artist).

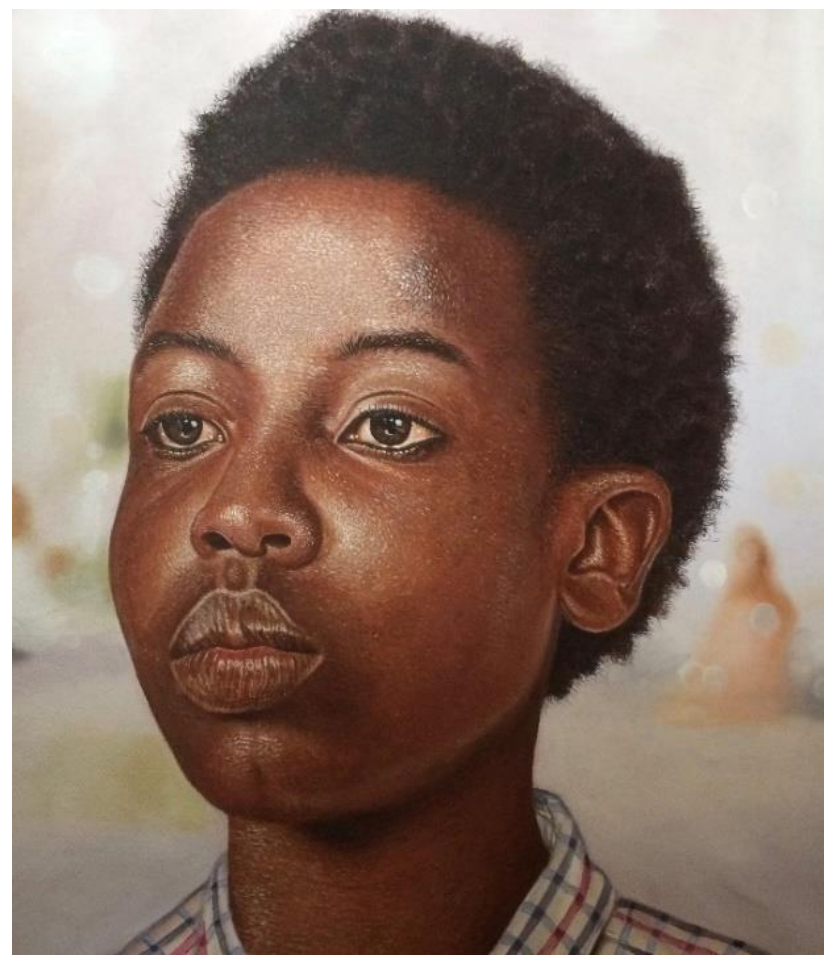

Plate 9: It is time;Size: $150 \mathrm{~cm} \mathrm{x} 100 \mathrm{~cm}$; Medium: Oil on canvas; 2017

Plate 9: This is a portrait of a young Kenyan girl staring into the future (Artist).

Plate 9 depicts a youthful girl. The use of the focused gaze depicts a feeling of youthful alertness, grace and determination. The hyperrealism brings out the very sharp eyes and full, smooth skin shown through the variation of tones and lighting effects, as well as the use of texture that depicts her dense hair.
Alpha (Plate 8) is the depiction of the continuation of the theme of the confluence of culture and modernity with a young man adorned with a large ostrich feather headdress; the suit is a modern attire, so is the red shiny leather seat which are all executed with admirable detail.

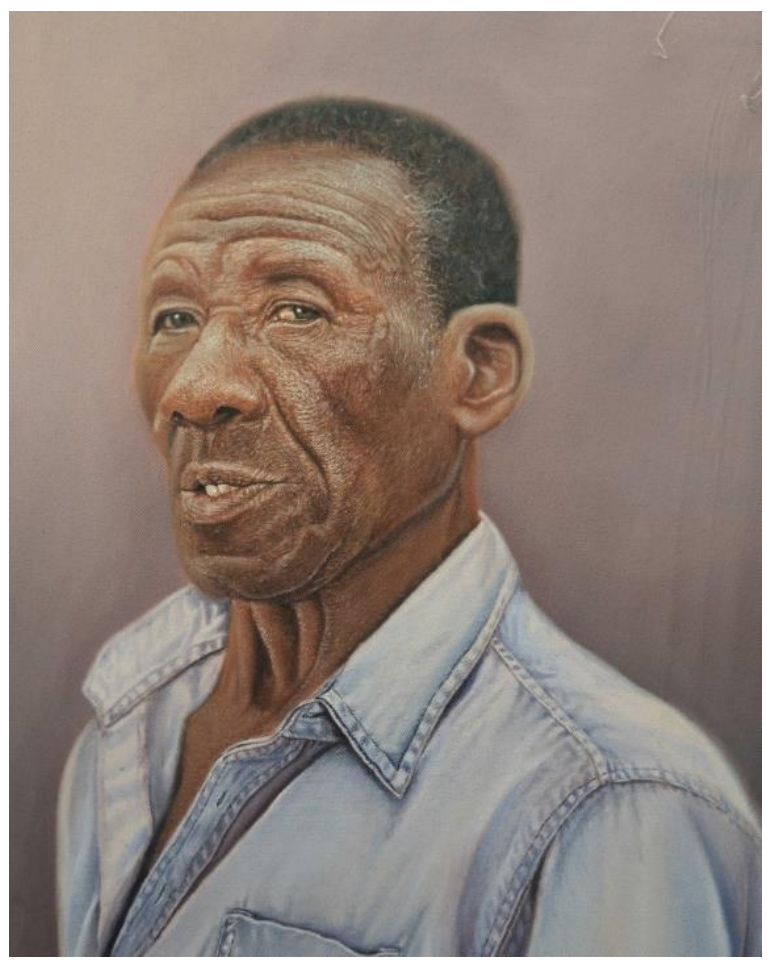

Plate 10: Courage; Size: $55 \mathrm{~cm}$ x $70 \mathrm{~cm}$; Medium: Oil on canvas; 2017

Plate 10. This is a portrait of a man I met in Nairobi. I saw him halt traffic on a busy road to allow an older lady to cross the road. In my eyes, he was a hero; I saw courage and selflessness (Artist).

Courage (Plate 10) depicts a portrait of a man whose facial execution shows a very high degree of detail and facial structural precision which is characteristic of hyperrealism. The 
facial colour tones are so well blended that the subject looks unequivocally natural and alive. The use of dark tones and shadows helps to create a feeling of roundness and the illusion of depth. There is also the intricate use of textural effects on the hair and on the skin that makes it appear rugged, clean-shaven and slightly sweaty. Facial skin folds on the forehead, side of mouth and neck help to emphasise the ruggedness of the face as well as the struggles of life. The casual demeanour of the subject, his posture as well as his faded attire suggests that he is some kind of labourer.

In terms of interpretation, the subject, unlike the Mundari young man (Plate 6), for instance, does not project an image of radiant selfconfidence; his is an image of a struggling individual. It can be said that although hyperrealism is very engaging, not all portraiture depicts meaning as intended by the artist; at times the viewer derives his or her own

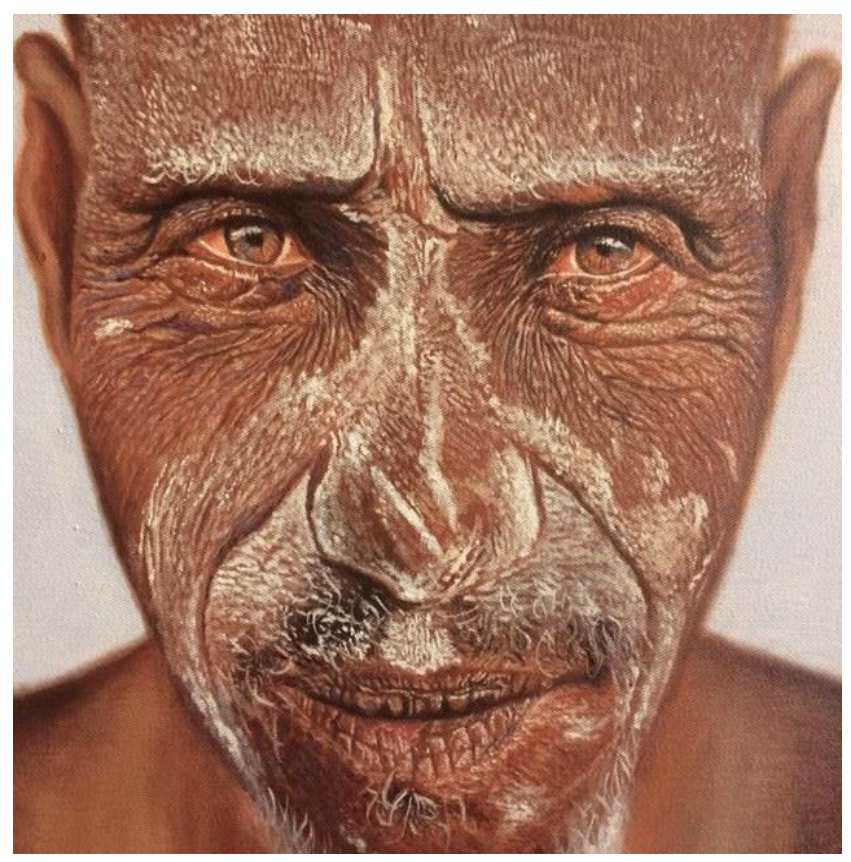

Plate 11: Untitled; Size: $60 \mathrm{~cm}$ x $80 \mathrm{~cm}$; Medium: Oil on canvas; 2019 interpretation. This is not unusual and falls within the realm of interpretational complexities. Barret (1994) identifies one of the principles of interpretation as 'an artwork is not necessarily about what the artist wanted it to be about'. The brief narrative by the artist on this portrait does not necessarily translate into what the viewer derives from the image. The artist did not delve into the background of the man, only on the short-lived moment of his perceived heroism. Instead, one may wish to interpret the subject through his gaze, his posture and demeanour, and perhaps even his attire. The gaze in this man's eyes is not about 'who he is' (Hensher, 2005); he is no hero, and probably would not be too perturbed about whether or not anyone wishes to delve into the content of his 'character' or 'personality'. He gazes at the viewer with the simple symbolic message that he just wants to be left alone to plough on with his life's struggles.

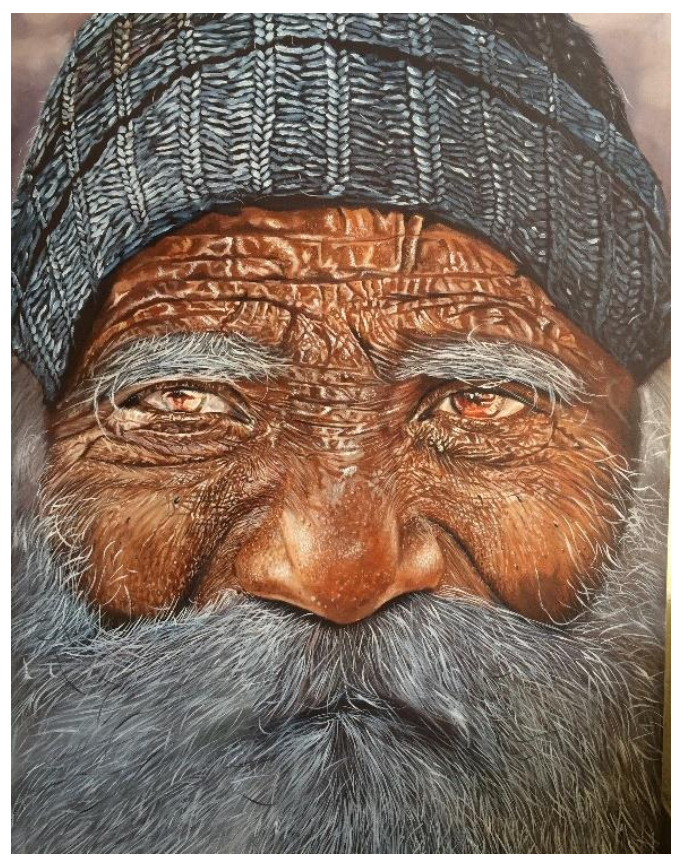

Plate 12: The eyes have it; Size: $100 \mathrm{~cm} \mathrm{x}$ $150 \mathrm{~cm}$; Medium: Oil on canvas; 2016 
In Plate 11 the artist concentrates on facial features of the Mundari tribal elder from Southern Sudan depicting the nature of the skin, including the minute skin folds and wrinkles. The same detailed skin study is done on the lips. This is done by applying various tones of the skin colour to meticulously depict the wrinkles and follow their precise contours giving them probably more clarity than a photograph would actually show. This activity is then concentrated around the eyes to emphasise the usual skin pull around the eyes. The artist goes on to study the eyes with a clear emphasis on the eyebrows that in turn helps to indicate the eye sockets and ultimately, the placement of the eyes themselves. The study of the eyes culminates in the somewhat inquisitive sharp gaze which is directed at the viewer. By virtue of his facial demeanour, it seems unlikely that this subject intends to express or communicate anything particularly subtle only perhaps to indicate to the viewer, through his gaze, that 'he is who he is'. Beyond that, the subject only poses to display the cultural white ash on his face.

Plate 12. This is a portrait of an old Aborigine man from Australia. The eyes are so striking, they draw all the attention. The eyebrows are also significantly hairy and the men would often let their facial hair grow to great lengths as a feature of their identity (Artist).

The eyes have it (Plate 12) features an elderly aborigine man with details executed such as wrinkles and folds meticulously inserted, perhaps so much so that the forehead appears a little waxy, an effect which is a direct result of the exaggeration of hyperrealism. His eyes bear that hyperrealistic focus or 'gaze' (similar to Plate 11) again caused by a concentrated study of the eyes themselves and the skin texture around the eyes that make them appear sharper and more piercing than they would normally appear on the photograph. This is a fundamental signature characteristic of hyperrealism; to focus detailed attention upon the subject's face, in order to make him or her appear alive and tangible. The artist also features other cultural objects like the finely detailed traditional beanie hat that underscores the fact that hyperrealism as a style is very useful for cultural propagation because of its very accurate rendition of detail. The two portraits are a good example of the difference between hyperrealism and photography from which the reference is derived. The use of textures, colour tones, lighting effects as well as the application of meticulous details are all harnessed to create an illusion of a fresh reality that is not present in the original photo of reference. It can be said that hyperrealism ultimately makes the photographs of reference redundant since each of the two portraits transform into a new work of Art.

Plate 13. Turkana Elders (Kenya) overlooking a dried-up field with pain and confusion in their eyes. Drought makes life unbearable for pastoralist communities. Pasture dries, cattle die and water becomes scarce. The elders usually have a tough responsibility in such situations of finding better land and resources for the whole community (Artist). 


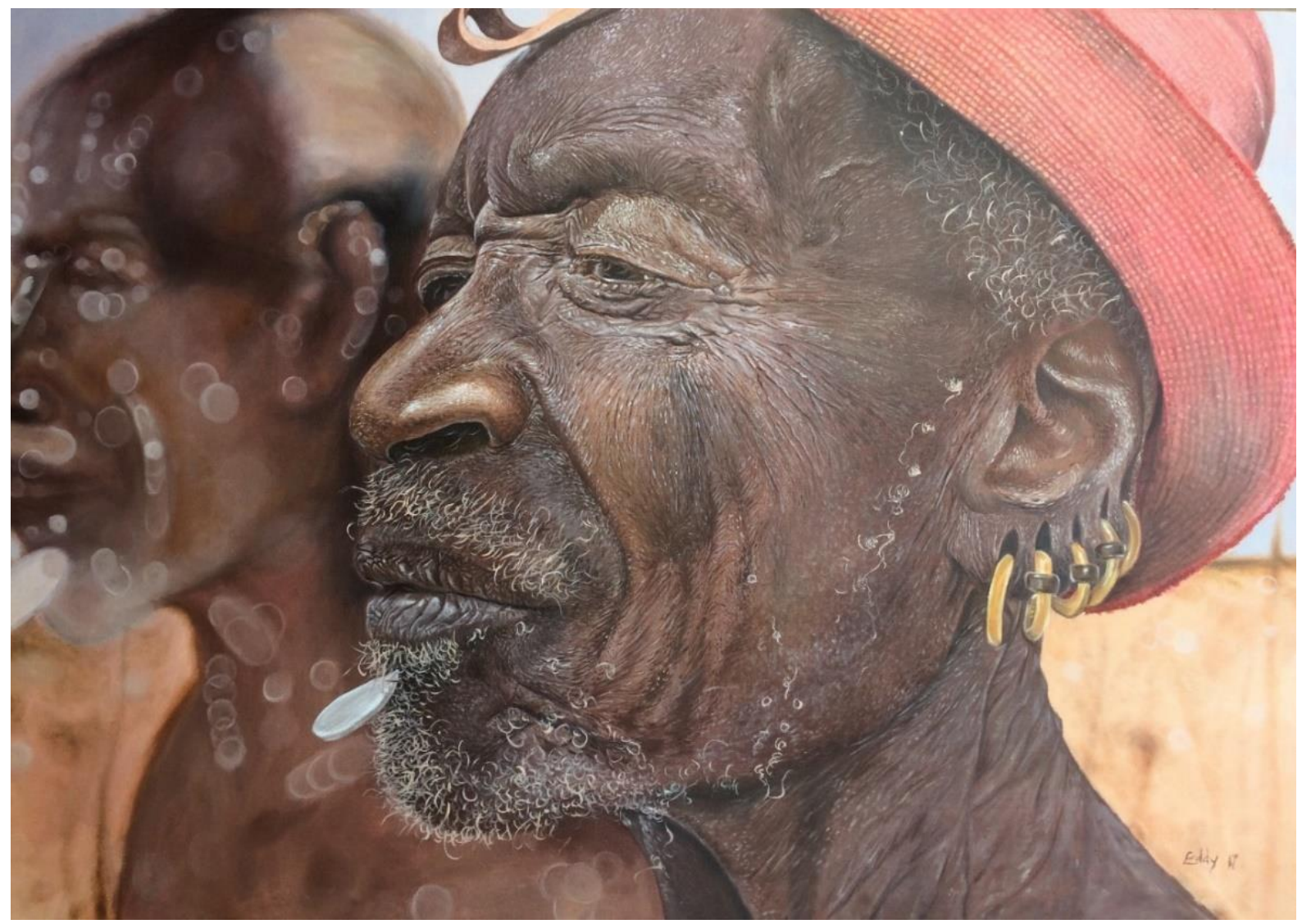

Plate 13. After all these years; Size: $95 \mathrm{~cm}$ x $145 \mathrm{~cm}$; Medium: Oil on canvas; 2017

The main purpose of hyperrealistic portraiture is to depict details that would otherwise be difficult to detect in a photograph. The portrait after all these years (Plate 13) that features the image of a Turkana elder is an outstanding example of the essence of the style itself. The study of the ageing skin on the face and neck with layers of minute wrinkles is a piece of creation to behold in its own right. The execution of the lips and their crackling skin is well focused upon, emphasising its own weathered dryness. The facial structural details are well constructed emphasised with variations of skin tones and facial contours that help to create the complete facial description. This includes the elongated nose, cheekbone, brow and even the all-important frown of concentration that gives the subject a hint of character. The artist also takes time to study the diminishing beards and hair including the remnants of what would have been the sideburns. As a piece of creation, the artist combines the details of hyperrealism on the foreground face of the subject with the faded background facial figure of the second but insignificant man, the contrast between which helps to emphasise the subject himself seen particularly by the use of the dividing dark tone between the two faces. Still serving the visual cultural purpose, the portrait depicts African cultural labrum piercing and ear lobe piercing as aspects of inherent Turkana culture. As is the case with other portraits, the artist gives attention to the eyes, carefully constructing the wrinkles around them and creating the sharp but distant gaze that gives the subject the sense 
of being physically alive but preoccupied seemingly by some conflict in his mind. The artist's narrative, however, helps to explain the distant gaze in the eyes of the man that betrays a hint of sadness and despair; one can hence empathise with him on account of his loss.

\section{OVERVIEW - THE VISUAL ESSENCE OF HYPERREALISM ON PORTRAITURE}

It can be said that the portraiture featured in this paper contains a level of detail that creates new works of Art derived from the original reference photograph, consistent with hyperrealism. In some of the portraiture, the level of detail is very refined and intricate creating faces that would ordinarily be lacking of such details either on a photograph or in real life, creating a new reality (Plates 3,4, 10, 11, 12, 13). These levels of detail attract attention to the work itself providing a new impetus for expression or communication. As a result of the portraits first attracting attention to themselves, they are effectively used as 'conduits' for the propagation of certain cultural elements. Descriptively, upon the first encounter with the portraiture, the viewer is fascinated by the execution of very intricate detailing as well as the absolute structural accuracy of the faces. This is characteristic of hyperrealistic work where the viewer is 'shocked' into complete visual submission. This initial 'shock' effect does not manifest itself upon viewing a regular photograph simply because a photograph lacks these intricate added details that captivate the eye. It has been argued, subsequently, that one of the most effective visual strengths of hyperrealism when applied to any work of Art is its ability to subject the human eye to a new reality that draws complete attention and prompts human beings to comprehend matters that hitherto had escaped their attention.

From an analytical perspective, elements such as line, colour and colour tones, textures and use of light and shadows are utilised to construct the portraiture in resonance with the technique used by the artist. It is evident that the artist uses the portraiture at this stage to communicate a cultural message by each portrait becoming a 'ride on' or as a conduit. It is notable that these are not just any other portraits, neither are they merely photographic; they are hyperrealistic. As noted earlier, this style first captures the attention of the viewer and then redirects this attention to whatever other mandates the portrait carries. In Plate 13, for instance, one only recognises that there is a depiction of cultural labrum piercing and ear lobe piercing as an artistic 'visual addendum' to the beautifully executed face. Likewise, in Plate 4 one notices the metal peg that stretches the ear lobe only in the holistic context of the very detailed face which lends it its significance. Hence, attention is 'cascaded' from the powerfully executed face to the stretched ear lobe.

In Plate 11, one is first attracted by the piercing eyes and the wrinkled face before noticing that the subject is painted with white ash; and in Plate 12, the traditional beanie or hat would not be visually apparent without the very intricate skin and equally piercing eyes which first draw the viewers' attention; in rebirth (Plate 1), the serene face of the Maasai woman with her amazing facial folds and well-textured lips and water almost submerging her face, is what first strikes the eye before the eye wanders on towards the ornaments on the forehead. The visual culture aspect is, however, not lost or 
diminished in all the portraiture; it is indeed enhanced since it is carried along by the overwhelming attraction that each of the portraits draws. This is ultimately the essence of hyperrealism in portraiture as a propagative tool for a desired message.

As earlier observed, unlike photorealists, hyperrealists add emotion, intent, narration and feeling into their work. This refers to all hyperrealistic work, but in particular reference to the featured portraiture in this paper, this factor manifests itself in a manner that is visually significant. It is intertwined with the age-old question about the purpose of portraiture. Hence, from an interpretive perspective, it can be deduced from some of the portraiture featured in this paper that it is possible for an image to express meaning beyond the depiction of physical likeness. It can also be deduced that at times, it is the intent of the artist to use portraiture to express a phenomenon, much more than it is an intent to bring out the physical likeness.

The artist, however, out of necessity, has to arrive at a confluence of the two intents in order to achieve this objective. In rebirth (Plate 1), the artist gives a glimpse of his motivation for the portrait, ostensibly speaking on behalf of the subject, when he writes about the Maasai woman, 'Almost a show of her dipping in for rejuvenation for her to spring back to life. When culture is rightly upheld, it propels us back to life, with a well-defined sense of identity and purpose'. This opinion may have perhaps arisen from a conversation with the woman herself or may have been concretised out of the observation of a cultural event. The artist, therefore, embarked on the portrait with the 'first intent' to depict this opinion but needed to have the subject's face as the tool through which to express this opinion using hyperrealistic features, which was of necessity, the 'second intent'. It is observed that the woman's face is extremely well executed with details that make her appear natural and serene, transformed as it were, into another realm of cultural rejuvenation. The subject, therefore, becomes not just another elderly woman whose face is almost submerged in water, but an expression of a social/cultural message.

In Time and chance (Plate 3) the artist writes a short narrative about the conversation with the real-life individual who asserts that 'everyone has their appointed time'. With this statement in mind, the artist then proceeds to depict the subject in a superbly executed side portrait. However, it is not possible to visually depict the assertion that 'everyone has their appointed time'. It can only be symbolised by the expression on the painted image that depicts an 'intensity' and 'resoluteness of character' that perhaps reflects the underlying resolve to wait upon his appointed time to fulfil his destiny or whatever weighs upon his soul. Subsequently, this portrait becomes not just another wellexecuted side view of a bearded man, but the hyperrealism becomes a lens through which the viewer glimpses into the soul of this man.

The intricately executed face of the old man (Plate 4) raises the question again about what portraits communicate beyond the physical likeness of the subject and whether they tell the viewer something about the character of the subject. Viewing the hyperrealism of the eyes and facial demeanour of this old man, there is no reason not to believe that he bears compassion because that is what the viewer is made to 'feel'. The allegorical possibility, on 
the other hand, would be that the old man probably bears a heinous underlying character; this could be true, indeed, but hard to fathom. Does the hyperrealistic visual depiction of a subject then 'sanitise' the real character and personality that is not visually discernible? Or does it in other circumstances do the opposite; does the hyperrealistic visual depiction of the face present the subject as bearing a heinous character thereby desecrating the real humane character that is equally not visually discernible? These questions certainly will linger. The real character and personality of this old Maasai man shall perhaps never be known; viewers of portraiture need not meet the subjects, but based on the hyperrealism of his portrait and the way the viewer examines him in minute detail is akin to delving into his 'personality' and 'character'. In terms of interpretation, based on visual interaction with the portrait, it can be inferred that the subject is, from an angle of visual perception, a man of peaceful demeanour; perhaps empathetic, perhaps kind.

Culture and modernity perhaps have a rendezvous. In dauntless (Plate 6) the portrait of a young man depicts both cultural and modern perspectives, hence the subject himself is a confluence of the two. The poise in the subject's face which is interpretable as a visual element depicts a person who is 'enlightened', which is symbolic. The poise itself is underscored by the spectacles and the inquisitive gaze which denotes that this young man is no ordinary village tribesman; yet he remains true to his culture, underscored by the white ash and the scarring of the forehead. The use and impact of the 'gaze' are not new in portraiture; it is often a very powerful tool of self-expression. Hensher (2005) observes,
'When we look now at a portrait that uses the direct gaze, ....we feel that the painting has created a hero, or heroine; we have someone saying: "This is who I am," with their direct and unreadable expression'. Hensher hence suggests, as in the case of the young man gazing directly at the viewer, that the subject (or the sitter) attempts to explain himself, to unravel a little of his character, to invite the viewer to his space even if only momentarily to understand him. Hensher concludes, 'but we feel, too, that the painting is saying "you" to a crowd of anonymous, shadowy people: people like us, evanescent, and slipping for a moment into unseeing inspection'. The hyperrealism of the portrait of the young Mundari tribesman, therefore, aids in the expression of a fundamental statement about the confluence of culture and modern life, which seems to have been the intent of the artist.

Technique used by the artist:

My first process is choosing a subject. In most cases, I will have a subject pose for me to take photos which I would then use for my reference. I'm always keen to take highdefinition photographs since this has a lot to do with how detailed the painting will turn out to be. I use a smooth canvas, primed with a toned primer (mostly grey or brown). My next step is sketching; I usually sketch freehand with a thin brush and thin acrylic paint. Accurate sketching really matters since this is a crucial step in the accurate representation of the subject. I then paint using oil paints, starting with the dark areas and shadows, very light layers with Burnt Umber or Burnt Sienna, then followed by the lighter colours. This helps me define volume 
and solidity as well as how light and darkness will fall on the subject.

The layering continues until there is a fairly smooth outcome of skin tones at which point it almost looks complete. The final stage, which consumes the most time is the addition of details. The aim here is to 'mature' as much details as possible. This is where different textures are also well defined. I use a small and soft range of needle-thin brushes for this process. The skin pores are achieved by putting dots of darker and lighter shades of the underlying skin tone together, in some instances, following a pattern and sometimes just haphazard; a process similar to neoimpressionist pointillism which needs maximum concentration and patience. I use a variety of brushes in general: Soft, hard, round, pointed, flat etc. for capturing different textures and covering different areas

\section{CONCLUSION}

Portraiture can be used to express emotions even though those emotions are not necessarily spoken. In rebirth (Plate 1) the artist is able to bring out the unique serenity of the face that depicts it as being completely at peace. The subject, of course, cannot speak but is overwhelmingly suggestive of what the innate emotion is. This paper posits that it is, indeed, possible to see or make out what permeates through a visual image; it is possible to make out what a visual image is intended to bring through. Some emotions, like the feeling of serenity, are not easy to visually depict, as compared to anger or laughter but the artist studies this very well and goes on to suggest, by extension, that the serenity here alludes to 'rejuvenation'. One cannot artistically depict rejuvenation but an artist can use another visual concept to depict it. In this case, he uses the concept of 'serenity' which he depicts as being present in the interaction with water, to provide the window through which the feeling of rejuvenation can be implied.

In Time and chance (Plate 3) the subject is communicating something to the viewer, it is as if he is telling the viewer that he has something to say. The portrait itself has a demeanour that is characteristic of the style of the artist; it is not obviously expressive; the subject is not shouting or crying or showing distress, he is silent but reflective. This is an interesting aspect of the hyperrealism of this artist that denotes the ability to show innate feeling without the usual bold facial expressions that are evident in most portraiture and upon which most artists rely. It can be concluded then that it is possible to depict a feeling of displeasure, simmering discontent, or even anger even though one cannot tell what the genesis of the feeling is since one can only do so by talking directly to the individual in real life. The artist does not disclose what the man referred to when he says everyone has their appointed time.

Whatever the motivation was for that statement, the artist goes ahead to depict a man who is clearly aggrieved about something that he feels he must let off his chest at some appointed time in the future, which appears like something that shall ruffle many feathers. This paper postulates that portraits do often tell a story; they often have something to say or what Barrett (1994) refers to as a certain "aboutness", which is a very good visual strength. We need not necessarily know exactly 
what the subject is thinking about; we only need to see that he or she is thinking about 'something' so that by that alone we may feel empathetic. It is true that since subjects featured in portraits cannot 'talk' literally, it is impossible to get into the minds of the real persons and that often raises allegorical questions. However, that is why portraits are painted in the first place, that is why they are so engaging; to emanate a visual determination of what the subject could be been alluding to through visual expression as depicted in the image.

The portrait after all these years (Plate 13) is very finely executed and as a new piece of creation is pleasant to view. The portrait (Plate 11) displays a level of detailing that is almost peculiar as one's eye scans the nature and texture of the facial skin, the minute details of its folds and wrinkles, the sharp and piercing gaze of the eyes and the texture on the skin of the lips. The eyes have it (Plate 12) emphasises the forehead skin making it look almost waxy but the wrinkles are themselves very well layed put. The eyes show some character, almost of wisdom and the texture on the head beret is very intricate. But it can also be interpreted, perhaps, that although each of these portraits (Plates 11,12 and 13) bear depiction of an element of facial character, it is not apparent that the subject intends to express anything in particular; they bear no expression that is relatable to a situation that elicits a given feeling or emotion such as distress, anger, laughter or even serenity, like is often evident in many other portraits, which then enables the viewer to derive some degree of empathy towards them. These kinds of portraits, although finely executed, bear a form of static demeanour; that is, they bear no depiction of relatable facial expression.

From an interpretive perspective then, this indicates that they are not inspired by any emotional engagement from either the subject or the artist and hold nothing else other than bearing a 'pose'. However, since they draw so much attention to themselves because of their superb rendition of detail, they are often effective for purposes of visual propagation of cultural peculiarities. It can be concluded, therefore, that some hyperrealistic portraits, though static in demeanour are a very effective tool for visual culture purposes because of their degree of visual clarity. This visual clarity is key in the depiction of adorned cultural items and traditional paraphernalia as well as other cultural peculiarities. In the context of this paper, this conclusion is further aided by the notion that cultural enthusiasts and other viewers prefer to view cultural items that are depicted as accurately as possible to the real objects as they exist in real life; there are neither cubist lip Plates nor abstract ear piercings.

This paper includes the artist's anecdotes of his inspirations for his portraiture. It is evident that in some portraiture where the brief narrative of the artist's inspiration is factored in the formative interpretation, it is significantly helpful in clarifying the meaning of the portrait when considered simultaneously with the rest of the visual analysis. For example, in the portrait after all these years (Plate 13) the face of the Turkana elder is very well executed but bears an almost enigmatic distant gaze. When the artist's narrative about the tragedy of drought and the loss incurred by the old man and his fellow tribesmen is factored in the 
interpretation, then the gaze manifests the pain and despair. Hence, the demeanour on the face is clarified and understood, and one can now 'see' the sadness and uncertainty resulting in the viewer being empathetic.

In the absence of this anecdotal intervention, the viewer may miss a major cue that is not visual but which is pertinent in the mind of the artist. However, it must be emphasised that this phenomenon is not always applicable in all portraiture or in all circumstances. In other instances, the artist's narrative may have no significant influence on how a viewer interprets a given portrait. For example, the artist's brief narrative about the exploits of the man in the portrait courage (Plate 10) does not prevent the viewer from interpreting the man as a struggling labourer. The hyperrealism in the portrait directs the interpretive trajectory in a different direction from that of the artist's narrative. This is not unusual, Barrett (1994) observes that 'the objects of interpretation are artworks, not artists. The interpretation of portraiture (or any other work of Art) to draw meaning can be viewed from different perspectives and therefore can be complex and emotive. In explaining this, Barrett notes that 'No single interpretation is exhaustive of the meaning of an artwork and that 'Interpretations are not so much absolutely right, but more or less reasonable, convincing, enlightening, and informative'.

It can also be concluded that not all hyperrealistic portraiture feature images that necessarily carry specific impactful messages on pertinent issues, ideas, or emotions that are a result of a specific 'intent' by the artist. Barrett notes that 'Some artists do not work with specific, conscious intentions to express particular and definite ideas. Some are quite comfortable having no specific intent while they are working'. In the untitled portrait of a man (Plate 11) the subject, though superbly executed, gazes directly at the viewer but exudes no particular pertinent message other than displaying the white ash painted on his face as a cultural peculiarity. That may have been the only intent of the artist in this portraiture.

From the foregoing, it can be concluded that hyperrealism as a style bears high creative impulsion that results in significantly more visual impact than a regular photograph would provide in similar circumstances. Hence there exists adequate justification for the technique of working on a photograph as a reference resource in order to visually develop and transform it into a 'new reality' which turns out not only to be a worthy new visual 'phenomenon' but a durable and exciting artistic style that shall continue to be exploited by many artists.

\section{REFERENCES}

Barret, T. (1994) Criticising Art: Understanding the Contemporary. Mountain View, California: Mayfield Publishing Company. Accessed October 8, 2020

https://pdfs.semanticscholar.org/35f5/5076 3b8b83fd733914cdf719b6ae356cb1b4.pdf

Bent, W. (2013). The Difference between Photorealism and Hyperrealism. Retrieved on October 6, 2020 from Ezine Articles, https://ezinearticles.com/?The-DifferenceBetween-Photorealism-andHyperrealism\&id=7873664 
Cichanowicz, L. (2017). Intimate strangers? Retrieved on Accessed October 9, 2020 from The Culture Trip, https://theculturetrip.com/europe/germany/ articles/10-jaw-dropping-works-ofhyperrealism/

Gersh-Nesic, B. (2019). Defining Portraits and Portraiture in Art. Retrieved on September 28, 2020 from Thought Co, https://www.thoughtco.com/definitionportrait-and-portraiture-183227.

Hensher, P. (2005). Intimate strangers? Retrieved on October 8, 2020 from The Guardian, https://www.the guardian.com/artanddesign/2005/jun/11/art

Lansroth, B. (2015). Hyperrealism in Art Ultimately, Is It Art or Skill? Retrieved on October 1, 2020 from Widewalls, https://www.widewalls.ch/magazine/hyperr ealism-art-style.

Muoka, C. (2017). Hyperrealism: Art or a show of skill? Retrieved on October 9, 2020 from Guardian.ng, https://guardian.ng/life/culturelifestyle/hyperrealism-art-or-a-show-ofskill/

Nairne, S. (2006). Why do painted portraits still matter? Retrieved on October 6, 2020 from Portrait.gov.au, https://www.portrait.gov.au/magazines/20/ why-do-painted-portraits-still-matter

Pereira, L. (2015). What is Portraiture in the Context of Contemporary Art? Retrieved on October 6, 2020 from Widewalls, https://www.widewalls.ch/magazine/painti ng-people-the-magic-of-portraiture
Taggart, E. (2018). The Evolution of Hyperrealism: From Religious Paintings to Simulated Reality. Retrieved on October 9, 2020 from Mymodernmet, https://mymodernmet.com/hyperrealismhistory/ 